\title{
Challenges in extending sustainability across a transport supply chain
}

\author{
Helena Forslund \\ School of Business and Economics, Linnaeus University, Växjö, Sweden \\ Maria Björklund \\ Department of Management and Engineering, Division of Logistics and Quality Management, Linköping University, Linköping, Sweden, and \\ Veronica Svensson Ülgen \\ School of Business and Economics, Linnaeus University, Växjö, Sweden
}

\begin{abstract}
Purpose - Sustainability approaches across product supply chains are well-known, while similar knowledge on transport supply chains (TSC) is limited. The purpose of this paper is to explore sustainability approaches and managerial challenges in extending sustainability across a TSC.

Design/methodology/approach - This paper presents a case study of a TSC with a shipper, a third-party logistics firm and a hauler. Each actor's views on sustainability-related communication and relations with other TSC actors are analyzed through the lens of agency theory.

Findings - Each dyad in the TSC reveals different, more or less collaboration-based approaches. Challenges are revealed, including the lack of shipper understanding for the TSC context and the use of immature contracts, which disincentivizes sustainability compliance. The multi-tier study object reveals the silencing of distant actors and the need for actors to take on mediating roles to bridge information asymmetries.

Research limitations/implications - Combining literature perspectives (relations, communication and agency theory) provides a deeper understanding of the approaches applied and identifies different challenges. The inclusion of agency theory reveals principal problems such as information asymmetries between agents and less-informed principals and suggests complementary labels of supply chain actors.

Practical implications - Practical contributions include the highlighting of managerial challenges, which can aid managers in extending sustainability across TCSs.

Social implications - The case study method offers insights into collaboratively improving sustainability in supply chains (such as using contracts), thus having social and environmental implications.

Originality/value - The paper narrows knowledge gaps about managing sustainability among logistics service providers and analyzes data from
\end{abstract} multi-tier actors.

Keywords Transport supply chain, Sustainability, Relations, Communication, Case study, Agency theory, Sweden, Communications, Transport operations, Logistic service industry, Goal congruence

Paper type Research paper

\section{Introduction}

Research on sustainability has expanded in focus from individual companies to supply chains, in which firms depend on the environmental (Gimenez and Sierra, 2013) and social (Awan, 2019) performance of others such as their suppliers (Villena and Gioia, 2018; Multaharju et al., 2017). Environmental performance can involve resource use and waste minimization and social performance can involve worker health and safety in supply chains (Awan, 2019; Sancha et al., 2016). Sustainability approaches that encompass several supply chain actors have been developed (Eriksson and Svensson, 2015; Gimenez and Sierra, 2013; Jiang, 2009). In line with others such as Meqdadi et al. (2020), in this paper the term "actor" is used for units such as companies or

The current issue and full text archive of this journal is available on Emerald Insight at: https://www.emerald.com/insight/1359-8546.htm

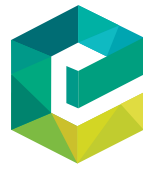

Supply Chain Management: An International Journal 27/7 (2022) 1-16

Emerald Publishing Limited [ISSN 1359-8546] [DOI 10.1108/SCM-06-2020-0285] organizations, acting within a supply chain. Sustainability approaches enable an understanding of such situations as to how buyers actively impose sustainability initiatives on passive suppliers or interact with suppliers to extend sustainability across supply chains. Sustainability may be more important to the actor that meets a consumer than to sub-suppliers that do not (Schmidt et al., 2017). This can generate managerial challenges in relation to how to extend sustainability ambitions and secure sustainable operations across multi-tiered supply chains (Meqdadi et al., 2020; Gong et al., 2018; Sauer and Seuring, 2018; Tachizawa and Wong, 2014).

Communication plays an important role in sustainable supply chain management. Communication was found to have

The authors would like to cordially thank the main funder, The Kamprad Family Foundation for Entrepreneurship, Charity and Research, Grant no 2016-0039 and the co-funder Vinnova, The Swedish Innovation Agency, Grant no 2019-03180, for making this research possible.

Received 13 February 2020

Revised 23 November 2020

8 February 2021

15 February 2021

Accepted 15 February 2021 
a direct impact on supply chain sustainability in an Australian manufacturing context (Jadhav et al., 2019) and on the development of relations (Biggemann, 2012). Furthermore, Ashby et al. (2012) noted the importance of addressing communication between actors in sustainable supply chain management. One point of departure for this study on exploring sustainability approaches in supply chains is to apply the perspective of the communication literature to deepen the perspective of the relations literature. Most companies communicate sustainability-related ambitions only in relation to their direct suppliers (Villena and Gioia, 2018). This calls for research on suppliers' ability to communicate buyers' sustainability-related ambitions across supply chains (in line with Wilhelm et al., 2016). Although previous studies recognized the important role of lower-tier suppliers in supply chain sustainability (Villena and Gioia, 2018), few studies on sustainable supply chains - even those described as multitiered - have captured data beyond dyads (e.g. the systematic literature reviews (SLR) by Ülgen et al., 2019 and Soosay and Hyland, 2015).

Different priorities of various supply chain actors can be a managerial challenge when execution is delegated across the supply chain (Kudla and Klaas-Wissing, 2012). Such a situation can be considered an agency problem (Eisenhardt, 1989 ) if the agent (supplier) behaves opportunistically to fulfill its self-interests instead of acts in the best interest of the principal (buyer) (Wilhelm et al., 2016; Shapiro, 2005). Goal conflicts are central to agency theory (Eisenhardt, 1989), a theory recognized as able to provide an understanding of behavior related to managing sustainability in supply chains (Wilhelm et al., 2016; Aßländer et al., 2016; Soosay and Hyland, 2015). Certain contexts are more susceptible to agency problems such as those where monitoring and measuring can be challenging. Little consensus exists among logistics service providers (LSPs) with regard to which measurements of sustainability to apply (Piecyk and Björklund, 2015). Few studies on supply chain sustainability consider the transport industry (Centobelli et al., 2020 and the SLRs of Ülgen et al., 2019 and Centobelli et al., 2017); additionally, despite LSPs being common actors in each supply chain interface, with a critical position for supply chain sustainability (Multaharju et al., 2017; Piecyk and Björklund, 2015; Evangelista, 2014), few studies include empirical data from LSPs.

Compared to service-oriented chains, product-oriented supply chains have been long (i.e. include many actors) for decades, and therefore need to manage agency problems (Meqdadi et al., 2020). However, a clear development can be seen wherein transport supply chains (TSC) become multitiered and include several sub-contracting actors ( $\mathrm{Li}$ et al., 2013), including fourth-party logistics firms (4PL), third-party logistics firms (3PL) and haulers; this makes them particularly relevant to study. The fragmentation of the transport industry, which consists of primarily small and medium-sized companies (Evangelista, 2014), may also entail specific managerial challenges for the shipper (the transport buyer and goods owner) in extending sustainability across the supply chain. Shippers need to put effort into interacting with the TSC (Lo and Shiah, 2016). The industry has also been identified as affecting sustainability approaches in multi-tier supply chains; for example, high-pollution industries tend to adopt a more proactive sustainability approach (Tachizawa and Wong, 2014). The managerial challenges experienced in extending sustainability in TSCs might differ from those in product supply chains (Meqdadi et al., 2020; Villena and Gioia, 2018). In line with this, Evangelista et al. (2017) called for studies on LSPs' initiatives to develop collaborative sustainability with subcontractors and $\mathrm{Li}$ et al. (2013) called for research on the coordination of the relations of multiple LSPs. Therefore, addressing TSCs would mean expanding and contributing to the knowledge on sustainability approaches in supply chains:

The purpose of this article is to explore sustainability approaches and managerial challenges in extending sustainability across a transport supply chain.

In the following, Section 2 presents the literature review, including the applied theoretical lens of agency theory. Section 3 provides information related to the methodology. Section 4 consists of empirical findings, analysis and discussion. Section 5 concludes the paper by highlighting the implications of the findings and recommending directions for further research.

\section{Literature review}

This section starts with outlining the core concept sustainability approaches in supply chains. Two literature perspectives are applied to establish and understand the sustainability approach: the "communication in supply chains perspective" and the "relations in supply chains perspective" (discussed in Section 2.1). Section 2.2 presents agency theory, applied to deepen the analysis of the sustainability approach and to support identifying managerial challenges. Operationalized concepts (italicized) are identified and linked together in the theoretical model presented in Section 2.3.

\subsection{Sustainability approaches in supply chains}

Two common ways of managing the sustainability of first-tier suppliers are the "extremes" of monitoring and collaboration (Hajmohammad and Vachon, 2016; Tachizawa and Wong, 2014). Monitoring, recommended in low-risk settings (Hajmohammad and Vachon, 2016), includes activities related to evaluating suppliers, while collaboration refers to directly working with suppliers such as by providing training or support (Gimenez and Sierra, 2013).

Monitoring and collaboration were conceptualized by Spence and Bourlakis (2009) into two sustainability approaches: a power-based corporate social watchdog (CSW) approach and a collaborative supply chain responsibility (SCR) approach. The CSW approach relies on a dominant actor in the supply chain who takes advantage of a powerful position to set and communicate sustainability standards for other companies. The CSW approach is primarily built on monitoring, wherein working with third-party auditors is one practice used to monitor lower-tier suppliers (Tachizawa and Wong, 2014). A collaborative sustainability approach, based on commitment and partnership, is proposed as an ideal next stage in development (Sauer and Seuring, 2018; Eriksson and Svensson, 2015). Based on the work of Spence and Bourlakis (2009), who take the collaborative aspects further, four farreaching key features are formulated that capture the essence of the SCR approach: 
1 A chain-wide commitment to achieving sustainability;

2 The legitimacy and possibility of all actors in the chain to have a voice;

3 A genuine partnership; and

4 Acknowledgment of the ethics of all supply chain actors.

Researchers have indicated that, in practice, the two approaches are more nuanced. From the perspective of the multi-tier supply chain, a direct and an indirect approach to sustainability are identified (Tachizawa and Wong, 2014), depending on whether the buyer has direct access to lower-tier suppliers or if the contact with lower-tier suppliers is conducted indirectly through another supplier (see also, e.g. Villena and Gioia, 2018). Based on studies of multinationals, Villena and Gioia (2018) noted that buyers often use both collaborationand monitoring-based approaches with their first-tier suppliers, whereas the first-tier suppliers primarily use the monitoring of the second-tier suppliers. Similarly, through their study of interactions for sustainability, Meqdadi et al. (2020) identified how monitoring in one tier often leads to monitoring in the next tier. Furthermore, the relation between monitoring and collaboration seems to be correlative (Tachizawa et al., 2015). Krause et al. (2000) identified that monitoring can act as an enabler of the collaborative approach, therefore suggesting that the collaborative approach can be built on buyer power. This was later empirically supported in an environmental context (Gimenez and Sierra, 2013) and in a social one (Sancha et al., 2016). Synergies have been identified between monitoring and collaboration when they are implemented simultaneously (Jiang, 2009; Lee and Klassen, 2008). For example, Gimenez and Sierra (2013) showed the importance of applying both approaches simultaneously in supplier development to reach the highest environmental output. Evaluating the suppliers' performance can be followed by collaborative efforts such as training, to enhance performance in identified improvement areas.

\subsubsection{Communication in supply chains}

Communication has been identified as playing a central role in collaborative approaches (Soosay and Hyland, 2015; Cao et al., 2010) and is identified as a collaboration mechanism for supply chain sustainability (Cloutier et al., 2020). Communication difficulties have been described as a primary cause of supply chain collaboration challenges, including conflicts, uncertainties and misunderstandings; however, at the same time, communication can solve many problems between suppliers and buyers (Aßländer et al., 2016; Cao et al., 2010; Paulraj et al., 2008; Mohr and Nevin, 1990). Therefore, communication from a literature perspective can enable the identification of managerial challenges such as those addressed in this paper.

Communication is commonly described, in the words of Mohr and Nevin (1990, p. 36), as "the glue that holds together a channel of distribution" (Sallnäs and Björklund, 2020; Cao et al., 2010; Kent and Mentzer, 2003) and it is linked to whether all actors have a voice. In their study of communication, Sallnäs and Björklund (2020) were able to illuminate the extent to which e-consumers had a voice (feature 2 in the SCR approach) so as to influence environmental transports. According to Jonsson and Myrelid (2016), communication and information sharing in supply chains are often presented through the four facets of Mohr and Nevin (1990): frequency, direction, mode and content. These facets are used in this paper as operationalized concepts of communication.

By aggregating these facets, Mohr and Nevin (1990) presented communication as autonomous or collaborative. Autonomous communication, marked by low-frequency, unidirectional flows, uses formal modes of communication and typically direct content (Mohr and Nevin, 1990). Formal modes are typically planned, routinized and structured (Mohr and Sohi, 1995). In line with Ghijsen et al. (2010), direct communication content seeks to change the communication partner's behavior by requesting the performance of specific actions such as making promises, adhering to legal obligations or threatening. Autonomous communication is expected to be found in a CSW approach, as this approach builds on monitoring and signals that the ambitions of the powerful actor direct the sustainability efforts in the supply chain (Spence and Bourlakis, 2009). Jonsson and Myrelid (2016) showed that the majority of information communicated via formal modes of communication (e.g. EDI, supplier portals) is unidirectional from the buyer, whereas informal modes of communication (spontaneous human-to-human contacts) are also used to convey information from the supplier. In this respect, informal modes can be seen as supporting the voice of the suppliers.

Collaborative communication is marked by a highfrequency, bidirectional flow, using both informal and formal modes and largely indirect content (Mohr and Nevin, 1990; Mohr et al., 1996). High frequency typically involves a greater amount of information, which often means higher-quality communication but can also result in information overload due to unnecessary information, which can create confusion or frustration (Mohr and Sohi, 1995). Bidirectional flows, including feedback on information received (Kembro et al., 2017; Mohr and Nevin, 1990), are necessary for suppliers to understand the expectations of buyers and for buyers to understand the capabilities of suppliers (Cambra-Fierro and Polo-Redondo, 2008). Feedback can come from a number of sources such as evaluation procedures and evaluation results (Prahinski and Benton, 2004). A bidirectional flow allows others than the dominant actor to find their voice and have it heard (Spence and Bourlakis, 2009). Informal modes of communication are typically personalized, irregular and somewhat spontaneous such as word-of-mouth contact. Indirect communication content seeks to align the attitudes of the communication partner with the desired behavior without explicitly requesting action (Mohr and Nevin, 1990). With its focus on direct content, collaborative communication is understood to reflect the collaborative sustainability approach, which assumes that no actor's ambitions or ethics have privilege over those of others (Spence and Bourlakis, 2009).

\subsubsection{Relations in supply chains}

The relations formed in sustainable supply chains and the communication that takes place therein are related (Ashby et al., 2012). Mohr and Nevin (1990) suggested that different forms of communication are expected, depending on different forms of relations. For example, Aßländer et al. (2016) proposed that a more trusting and supportive relationship allows for more frequent and more bidirectional 
communication. Jonsson and Myrelid (2016) identified a positive relationship between long-term, collaborative relationships and willingness to communicate. Communication is also proposed to have the ability to affect and develop the relations between actors in sustainable supply chain management (Aßländer et al., 2016). Furthermore, Cao et al. (2010) concluded that to evaluate the level of collaboration, the evaluating mechanisms must be based on both relationship and communication flows, which are relevant to evaluating sustainability approaches in supply chains.

Relations in supply chains can be described through the conditions of the structure, climate and power (in line with, e.g. Mohr and Nevin, 1990). Structure refers to the degree of interorganizational interaction, ranging from market structures (e.g. arm's-length relations) to relational structures (e.g. partnerships; Varoutsa and Scapens, 2015) that involve longterm relations, joint planning and considerable interdependencies. In multi-tier supply chains, the possible direct influence of an actor decreases as distance (physical, social or cultural) increases (Sauer and Seuring, 2018; Tachizawa and Wong, 2014), entailing managerial challenges in extending sustainability in supply chains. Increased distance between actors may also lead to increased information asymmetries (Wilhelm et al., 2016; Tachizawa and Wong, 2014) and a more diverse range of implemented sustainability practices. Climate refers to actors' feelings about the levels of trust and supportiveness in their relations. Power refers to the degree of power balance; it ranges from symmetrical to asymmetrical and can be based on the substitutability of supply or demand through the number of suppliers available, the perceived importance of the exchange based on the demand share (i.e. volume in relation to total volume) or reputation such as brand, expertise or knowhow (Pazirandeh and Norrman, 2014; Cox, 2001). Power is regarded as an important factor of social responsibility in supply chains (Eriksson and Svensson, 2015), which buyers can exercise by, for example, dictating how suppliers conduct their businesses. Buyer power or joint dependencies are observed as having a strong positive association with socially responsible supply chains, while supplier power limits social responsibility (Hoejmose et al., 2013; Cox, 2001). Lower-tier suppliers (Schmidt et al., 2017; Tachizawa and Wong, 2014) and smaller companies in the supply chains of larger companies (Multaharju et al., 2017; Faisal, 2010) may be less inclined to promote sustainability, as they do not experience strong stakeholder pressure because they are not well-known publicly or have no recognized brand to protect.

\subsection{Agency theory: a lens for deepening the analysis}

To further analyze sustainability approaches in multi-tier TSCs, the lens of agency theory is adopted. When extending sustainability in supply chains, the primary principle - i.e. the "prime leader" of the supply chain - may delegate work (related to sustainability) via its agent, the first-tier supplier, to another agent, the second-tier supplier (Cheng and Kam, 2008). This illustrates how the sequential nature of supply chains dictates that an actor can be a principal in one relationship and an agent in another (Wilhelm et al., 2016; Ketchen and Hult, 2007). According to Tachizawa and Wong (2014), the delegation of work throughout the supply chain requires primary-principal power. Agency theory helps identify the important and dual roles of the first-tier supplier or secondary principal - i.e. an agent who reports to the primary principal and collaborates with other agents to meet requirements. Wilhelm et al. (2016) conceptualize this as a double agency. In a TSC, this role may be especially important, as a 4PL typically coordinates several 3PLs (Vlachos and Dyra, 2020). Recently, Vlachos and Dyra (2020) applied agency theory to analyze interactions in triads (retailer-LSP-suppliers), where the LSP serves an important brokerage or coalition role in bridging information asymmetries in the collaboration. The study further identified situations where actors can have the power to configure new relations between principals and agents.

The underlying cause of agency problems is often goal conflicts in the relations (Schmidt et al., 2017; Kudla and KlaasWissing, 2012), driven by incentives that prevent alignment of the interests of agents and principals. Even when the actors aim to collectively create more value, they may still have partially conflicting goals, as they may want to gain a larger share or put forth less effort for the same reward (Ciliberti et al., 2011). This is illustrated by Kudla and Klaas-Wissing (2012) in a TSC sustainability setting, where certain agents disregard specific sustainability requirements and only implement so-called “quick win" activities. Conversely, Aßländer et al. (2016) found that the central notion of agency theory - i.e. the agent, if not controlled, takes advantage of the principal - is not always valid. Goal conflicts in a relationship may indicate that a chainwide commitment to sustainability (feature 1 in the SCR approach) or a genuine partnership (feature 3) cannot be achieved. The double agency holds the agent accountable for attaining goals in two ways: first, for implementing sustainability internally, in the primary agency role; second, for extending sustainability standards to its suppliers, in the secondary agency role (Wilhelm et al., 2016).

Another cause of agency problems is information asymmetries - when at least one actor in a relationship has more or better information than the other actor or actors - and the accompanying uncertainty and risk (Pratt and Zeckhauser, 1985). Information asymmetries demonstrate the consequences of insufficient communication related to frequency, direction and content. Kudla and Klaas-Wissing (2012) reported that buyers of logistics services seldom control or monitor whether their LSPs perform the required sustainable activities, indicating a risk for information asymmetries in the TSC. Accordingly, agents may keep valuable information to themselves to advance their interests or to disguise their lack of effort (Sarkis et al., 2011), which can indicate managerial challenges. Given that monitoring can reduce information asymmetries in supply chains (Tachizawa et al., 2015; Foerstl et al., 2010; Krause et al., 2000), monitoring is suggested as a first approach when extending sustainability across the supply chain. When an agent's actions are difficult to observe and assess - as is the case with increased distance in multi-tier supply chains (Wilhelm et al., 2016) - the principal faces an increased risk of agent opportunism (Fayezi et al., 2012). Kudla and Klaas-Wissing (2012) concluded that agency problems need to be circumvented to ensure that the actions across the supply chain are aligned.

To circumvent the agency problem and reinforce desired behaviors (Ketchen and Hult, 2007), a principal can offer 
incentives (Jensen and Meckling, 1976), including contracts. Two contract types are used as incentives to avoid agency problems and to formalize communication: outcome-oriented contracts and behavior-oriented contracts (Eisenhardt, 1989). Which contract type is preferred relates to the task and the context in which the agent performs the task. Outcomeoriented contracts focus on well-defined, measurable performance and involve specifying a delivery and linking it to payment (Selviaridis and Norrman, 2014); they can incentivize agents to behave in line with the interests of a principal. Such contracts are typically low-frequent, unidirectional and based on formal modes of communication, making them examples of autonomous communication (in line with Mohr and Nevin, 1990). In contrast, behavior-oriented contracts stress the required processes and activities that support performance; they are suitable when behavior can be specified in advance and monitored (Eisenhardt, 1989). When the measurability of an outcome is low, takes time to complete or delivers soft outcomes, behavior-oriented contracts are preferable (Selviaridis and Norrman, 2014). Here, higher-frequency, bidirectional communication using informal modes of communication is expected, which is typical for collaborative communication (Mohr and Sohi, 1995).

Studies have shown that even though environmental performance is often mentioned in transport contracts with LSPs, shippers do not necessarily specify how to measure environmental performance and how to handle noncompliance (Björklund and Forslund, 2013; Kudla and KlaasWissing, 2012), which may undermine the contract. These challenges may be even larger in the context of social sustainability performance (Awan, 2019), which is more difficult to specify and measure (Nakamba et al., 2017). Contracts with both outcome- and behavior-based clauses have been shown to align actors and lead to improved performance (Vlachos and Dyra, 2020). Norrman and Näslund (2019) emphasized the importance of avoiding goal conflicts, through joint performance goals and through linking process performance measures to incentives. Based on their study, they further identified that no primary principal (e.g. shipper) that has designed incentives for their suppliers, including LSPs, has also designed incentives for their second-tier suppliers.

\subsection{Theoretical model}

The sustainability approach that is applied is reflected in the communication and the relations formed. It has been found that a market structure, an unsupportive climate and asymmetrical power are associated with a CSW approach. In these conditions, Mohr and Nevin (1990) suggested that autonomous communication is expected; in imbalanced power conditions, less feedback may be needed because less-powerful actors are supposed to implement decisions but not participate in making them. More formal modes of communication are used to convey messages, especially persuasive ones such as contract information. The ideal function of the contract is to limit goal conflicts and information asymmetries, thereby regulating the sustainability approach. In contrast, the SCR approach is expected in conditions with a relational structure and a supportive climate. In line with the findings of Hoejmose et al. (2013) and Cox (2001), the SCR approach is most likely to occur in relations built on symmetrical power with interdependencies between supply chain actors, but it could also appear in relations characterized by buyer power. In relational structures and supportive climates where power is symmetrical, collaborative communication is typical, according to the framework of Mohr and Nevin (1990). The SCR approach - with its features of joint commitment, partnership and the authorization of the voices and ethics of all actors (Spence and Bourlakis, 2009) - indicates a situation without goal conflict and with potential information symmetries in the supply chain.

Figure 1 illustrates how agency theory (three concepts) is applied as a lens through which to view the literature perspectives on communication (four facets) and relations (three conditions). Together, these form a basis for deepening the understanding of which sustainability approach is applied (first part of the purpose). All the literature areas provide insights into the managerial challenges to extending sustainability across a TSC (the second part of the purpose).

\section{Methodology}

This section lays out the research design and sampling, as well as the data collection and analysis. Throughout the section, aspects of the study's rigor, validity and reliability are discussed.

\subsection{Research design and sampling}

To explore a seldom-examined phenomenon, it is important to interact with and gain empirical input from individuals who have experienced that phenomenon. In this context, a research design based on case studies is often appropriate (Yin, 2014). The study object is a TSC, with its dyads as the embedded units of analysis.

The goal was to identify and sample a TSC involving a shipper with high sustainability ambitions that was operating in the Swedish market and was willing to participate in the study. The geographic context of Sweden was chosen because of convenience (Bryman and Bell, 2011) and because it would offer the possibility to interview respondents in person. Furthermore, Centobelli et al. (2020) and Faisal (2010) found national differences in LSPs' environmental practices and demands; therefore, this context enables a study of actors under the same circumstances.

One shipper with exceptionally high sustainability ambitions was identified by contacting the CEO of a known environmentally ambitious LSP [1] (hereafter referred to as the 3PL). This shipper was a natural choice, as it is the only shipper

\section{Figure 1 Theoretical model}

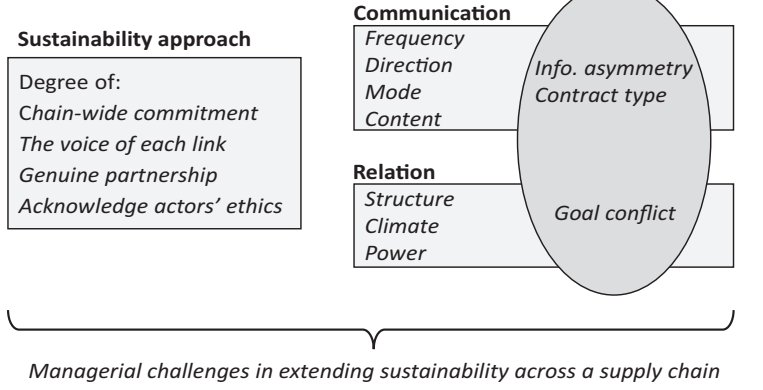


to include social requirements in its contract with the 3PL. A consequence of this sampling is that the TSC only includes road transportation, dedicated transports of full truckloads and no terminal actors. This TSC design enabled the study to isolate a single shipper's sustainability requirements and how sustainability is approached in the dyads across the TSC. The 3PL also identified one of the largest haulers subcontracted for this shipper. This TSC - consisting of the shipper, the 3PL and the hauler - was examined. The supply chain is, thus, operationalized as three interlinked actors, in line with, among others, Wilhelm et al. (2016). The shipper, one of the largest grocery retailers in Sweden, is an important shipper for the 3PL. The 3PL, a significant actor in the Swedish market, is cooperatively owned by approximately 80 haulers. Finally, the hauler is one of the 3PL's largest partners and one of the seven to eight haulers needed to transport the shipper's large volumes. The 3PL's CEO also advised targeting specific respondents - primarily CEOs, supply chain managers and environmental managers, which concurred with Evangelista et al.'s (2017) recommendation. Efforts were made to ensure that the respondents were knowledgeable about sustainability practices and about the relations and communication with the TSC actors. This was confirmed, as the respondents had long experiences with their companies, showing knowledge at different perspectives and levels. This was also true for the shipper's respondent, despite representing a large company. Using multiple respondents for data triangulation (Yin, 2014) strengthens the study's validity and reliability. The following companies and respondents were interviewed (see also their abbreviated titles, used when presenting the empirical data):

- Shipper: Head of sourcing logistics (HOS);

- 3PL: Chief executive officer (CEO), Key account manager (KAM) and Quality and sustainability manager (QSM); and

- Hauler: Chief executive officer and environmental sustainability manager (CEO-ESM) and Human resource and social sustainability manager (HRM-SSM).

\subsection{Data collection and analysis}

To ensure rigor and to increase construct validity, a semistructured interview guide was developed based on the literature on relations and communication, thus applying a deductive approach in line with recommendations by, among others, Yin (2014). Agency theory was applied as a theoretical lens for the analysis of the empirical findings, providing deeper analysis and enabling the accurate representation of the sustainability approach applied.

The questions were sent in advance to each respondent so they could prepare. Face-to-face interviews with the six respondents were conducted, with each interview lasting 40$90 \mathrm{~min}$. To ensure insights based on relevant responsibilities, respondents were first asked to describe their current position, title and personal history (e.g. how long they worked at the company, previous responsibilities and previous employment relevant to their present role). Then, they were asked to describe the TSC in general terms and the different actors in that chain. Each dyadic relationship was then investigated in isolation. For example, the hauler described the communication and relations in the direct dyad with the 3PL and those in the indirect dyad with the shipper. Open questions were followed up with probing to ensure that the concepts identified in the literature were covered (see questions in Appendix). Two researchers participated in and took notes during each interview; post-interview, the notes were consolidated and sent to the respondent for verification. For method triangulation (Yin, 2014), other data sources including sustainability reports, webpages, comprehensive educational information material and some measurement data - supplemented the interview data. Through clear documentation of the coding schemes, decisions and questions, which all followed case study protocol (Yin, 2014), the study's reliability was ensured. The empirical data were manually coded into an Excel document and structured around the core operationalized concepts, as well as the views of the various actors.

The analysis was conducted in three steps. First, the empirical findings were structured in accordance with the concepts that operationalize communication and relations. Second, agency theory was applied as a theoretical lens to the analysis of the empirical findings. In the third step, the insights from the literature perspectives were integrated, revealing the different features of the sustainability approach in each dyad and the associated managerial challenges in the TSC. Earlier, shorter versions of this paper were presented at conferences targeting both industry and the logistics/supply chain management research community. The ensuing discussions, particularly at the industrial conferences, strengthened the validity of the paper.

\section{Empirical findings, analysis and discussion}

This section starts by outlining the empirical findings for each dyad concerning communication (in terms of frequency, direction, mode and content) and relations (in terms of structure, climate and power). For traceability to the raw data, each actor's view on the communication and relations with other actors up and down the TSC, as well as illustrative quotes, are presented in Table 1. Based on the empirical findings on communication and relations and the application of agency theory, the sustainability approaches (characterized by the four features inspired by Spence and Bourlakis, 2009), are elaborated. Thereafter, managerial challenges related to extending sustainability across the TSC are identified.

\subsection{The shipper-third-party logistics firms dyad}

Both the shipper and the 3PL describe their communication as being low in frequency and controlled by the shipper. The communication has a formal modality: written, structured and planned. Both describe a long-term, positive, relational structure with a supportive climate and shared sustainability ambitions. However, the relationship is based on asymmetrical power and favors the shipper.

\subsubsection{Sustainability approach}

The dyad is represented by features that indicate a predominantly monitoring-oriented corporate social watchdog (CSW) sustainability approach. A dyad-wide commitment to achieving sustainability can be identified on an overall level, expressed in terms of mutual sustainability ambitions. The application of agency theory reveals a potential goal conflict. 
Table 1 Descriptions of sustainability-related communication and relation: Different actors' views

\begin{tabular}{ccll}
\hline Actor's view & In dyad with & \multicolumn{1}{c}{ Descriptions } & Illustrating quotes \\
\hline Shipper & 3PL & $\begin{array}{l}\text { Communication: Imposes environmental sustainability } \\
\text { requirements (e.g. regarding fuel type and } \mathrm{CO}_{2 \mathrm{e}} \text { /liter of } \\
\text { fuel) and social requirements (e.g. driving and resting }\end{array}$ & "It is clear which key performance indicators (KPIs) we \\
& times, safe vehicles, use of seat belts and driving & reporting is not yet mature and we require no KPIs due to \\
& licenses) in the contract appendix. These requirements & ambiguities in legislation, but 3PLs should report" (HOS). \\
& are not motivated by consumers, as they only & "We [however] see that we have a large responsibility \\
& for sustainability as a leading actor in the market" (HOS)
\end{tabular}

communicate product-related sustainability to the shipper. Requires the 3PL to ensure that all haulers uphold the contract and to report on all subcontracted haulers. Requires the 3PL to send monthly environmental reports. Audits are conducted once or twice annually by a third-party auditor. Receives more input from auditor than from the 3PL on the actions and sustainability performance

Relationship: The 3PL has been awarded many contracts by the shipper for different receivers and different types of goods for more than 35 years. This implies many different individuals involved in the relationship over time

Hauler Communication: The hauler is not large enough to transport all volumes for the shipper and the shipper wants to have just one transport supplier. Therefore, the shipper sees no need for communication with lower-tier suppliers and wants the $3 \mathrm{PL}$ to secure this communication, while still monitoring such suppliers via the 3PL and auditors. Auditors conduct unannounced spot-checks on operations (e.g. seat belt use and drivers' license of haulers) to ensure the sustainable performance Relationship: Does not seek any direct relations. The shipper cares about and is motivated to ensure its reputation as an attractive shipper. They impose high social sustainability requirements on $3 \mathrm{PLS}$, which, in turn, should be imposed on haulers

3PL Shipper

Hauler
Communication: Sustainability requirements are communicated in a contract appendix applicable to all the shipper's suppliers, including product suppliers, and therefore contain a lot of irrelevant and redundant information. The shipper requires formal, written sustainability reporting and auditing. The shipper is not open to in-depth discussions and feedback on requirements

Relationship: Long-term relationship, but not on a personal level, with this highly attractive shipper. The shipper has high sustainability ambitions that are in line occurs in a highly competitive bidding environment, where the contract can be lost or in which a competitor 3PL can turn into a sub-contracting 4PL. The shipper respects the 3PL's knowledge and does not micromanage vis-à-vis how social sustainability is operationalized, how work routines and tools are developed or how the demands for fossil-free fuel are reached

Communication: The shipper's contract is passed on to the hauler unedited. The shipper outsources the operationalization of social sustainability to $3 \mathrm{PL}$ and with the 3PL's own ambitions. The awarding of contracts
"We meet this 3PL on many levels" (HOS)

" 3 PLs should ensure that haulers and primarily drivers have good daily conditions" (HOS)

"Qualified drivers are a scarce resource; we have to
ensure that they want to drive for us" (HOS)

"This shipper was the first to impose environmental requirements five years ago. This year, they are the first to require certain social requirements" (KAM). "We estimate that $60 \%$ of the contract appendix applies to 3PLs" (QSM). "Despite our wish to communicate with the shipper about audit results, no such communication occurs" (QSM)

"A good shipper - able, educated and updated" (KAM). "A competitor was awarded a contract with this shipper, despite lacking the required capacity and they subcontracted us as a solution" (CEO)

"We email the contract appendix even if it contains redundant information" (KAM). "Maybe we should edit the appendix to include only information relevant to each 
Table 1

\begin{tabular}{|c|c|c|c|}
\hline Actor's view & In dyad with & Descriptions & Illustrating quotes \\
\hline & & $\begin{array}{l}\text { hauler. This necessitates frequent and in-person } \\
\text { meetings to discuss their responses to the shipper's } \\
\text { requirements and their adjustments in operations to } \\
\text { meet the sometimes-vague requirements for follow-up. } \\
\text { The shipper's demands for follow-up action require the } \\
\text { hauler to be monitored by the 3PL. The 3PL constantly } \\
\text { seeks more information about the hauler's operations in } \\
\text { terms of drivers and vehicles. Monitors legislation, which } \\
\text { motivates and drives the development of requirements } \\
\text { and, in turn, follow-up action. The 3PL requires all newly } \\
\text { employed drivers to sign contracts in which they promise } \\
\text { to adhere to the requirements and outsources the follow- } \\
\text { up through spot-checks to a third party }\end{array}$ & $\begin{array}{l}\text { hauler, but such action has not been prioritized" (QSM). } \\
\text { "Important messages might get lost in the fine print" } \\
\text { (KAM). "Some required information is available from an } \\
\text { independent company's app, ensuring that each vehicle } \\
\text { is inspected for safety every morning. Take the terror } \\
\text { attack in Stockholm; when a truck was stolen and driven } \\
\text { through pedestrian zones, it meant that we had demands } \\
\text { quickly put upon us to guarantee to lock and bring the } \\
\text { keys as soon as a driver leaves the vehicle" (QSM) }\end{array}$ \\
\hline & & $\begin{array}{l}\text { Relationship: The hauler has been one of the largest } \\
\text { partners of the } 3 \mathrm{PL} \text { for decades. Mutual trust and close } \\
\text { collaboration are described as key to making the } \\
\text { operational changes needed to reach the shipper's high } \\
\text { demands related to sustainability performance }\end{array}$ & $\begin{array}{l}\text { "We have aligned our ambitions and forged a mutual } \\
\text { understanding about sustainability" (CEO) }\end{array}$ \\
\hline \multirow[t]{4}{*}{ Hauler } & Shipper & $\begin{array}{l}\text { Communication: All communication goes through the } \\
\text { 3PL. The hauler wants more communication so as to } \\
\text { clarify the shipper's future requirements and motivators } \\
\text { for sustainability, particularly, as requirements often fail } \\
\text { to consider practical operational realities and can be } \\
\text { impossible to meet. The contract lacks non-compliance } \\
\text { clauses for sustainability requirements despite including } \\
\text { it for delivery requirements; if the two conflict, delivery } \\
\text { requirements take priority, with operations and } \\
\text { performance adjusted toward delivery requirements. The } \\
\text { shipper offered web education once, something which } \\
\text { the hauler would want every year - a requirement they } \\
\text { have asked the 3PL to forward to the shipper. The hauler } \\
\text { wishes to share transport-related data (i.e. fuel usage), } \\
\text { as they are proud of their measurement system and } \\
\text { performance, but the shipper shows no interest in this } \\
\text { data }\end{array}$ & $\begin{array}{l}\text { "Conventional requirements for on-time delivery can be } \\
\text { stressful, requiring both prompt delivery and respecting } \\
\text { speed limits and this counteracts rest times in unforeseen } \\
\text { situations such as in queues" (HRM-SSM). "[If] the } \\
\text { shipper expects us to carry their flag, then we have to be } \\
\text { updated about their demands" (HRM-SSM). "We want } \\
\text { the shipper to have the possibility to log on to our } \\
\text { measurement system at any time" (CEO-ESM) }\end{array}$ \\
\hline & & $\begin{array}{l}\text { Relationship: The hauler has had a long-term indirect } \\
\text { relationship with the shipper involving diverse types of } \\
\text { transports for different receivers in various locations. The } \\
\text { hauler desires to advance its position in the TSC and } \\
\text { thereby have a direct relationship with the shipper }\end{array}$ & $\begin{array}{l}\text { "We have driven for this shipper for many years; } \\
\text { however, the challenge is that the shipper has to } \\
\text { perceive us as one supplier - the 3PL - not 7-8 haulers" } \\
\text { (CEO-SSM) }\end{array}$ \\
\hline & \multirow[t]{2}{*}{$3 P L$} & $\begin{array}{l}\text { Communication: The received contract information is not } \\
\text { carefully reviewed; instead, the hauler relies on many } \\
\text { personal meetings with the 3PL. The 3PL asks (albeit } \\
\text { seldom) for detailed measurement data on sustainability } \\
\text { performance from the hauler. The hauler communicates } \\
\text { requirements for changed operations with drivers } \\
\text { (among other things) using apps, tracking tools and } \\
\text { online messages that are visible when the drivers record } \\
\text { their hours worked. The drivers must confirm that they } \\
\text { have received the message }\end{array}$ & $\begin{array}{l}\text { "Personal meetings are the best information channel, so } \\
\text { we hope to get all necessary information there" (CEO- } \\
\text { ESM). "I cannot know for sure that they [the drivers] } \\
\text { have read, understood and accepted the information } \\
\text { provided" (HRM-SSM) }\end{array}$ \\
\hline & & $\begin{array}{l}\text { Relationship: Longstanding and seen as based in } \\
\text { partnership because of cooperative ownership and a high } \\
\text { level of joint dependency. Perceives that the 3PL could } \\
\text { advocate for more realistic social requirements and for } \\
\text { their time-related non-compliance clauses }\end{array}$ & $\begin{array}{l}\text { "We have been a large partner of the 3PL for many } \\
\text { years" (CEO-SSM) }\end{array}$ \\
\hline
\end{tabular}


The monitoring of the agents, which can be considered a display of an unsupportive climate, also indicates that the principal experiences a risk of goal conflicts on an operational level. The principal and the agents may have different views of which actions to perform or how to perform them (similar to that identified in Ciliberti et al., 2011 and Kudla and KlaasWissing, 2012), making the principal inclined to monitor. In addition, the monitoring indicates that the principal has implemented a way of recognizing social sustainability (Awan, 2019), despite the difficulty of measuring it (Nakamba et al., 2017). The 3PL acknowledges the fact that the contract appendix contains redundant requirements, which are partly affected by consumers' product sustainability requirements and not relevant to the Swedish TSC context. By signing this demanding contract, the $3 \mathrm{PL}$ signals that no goal conflict is perceived and even signals its competence in meeting sustainability requirements, which represents a situation in which the 3PL could "shift back" some information asymmetry and act opportunistically (Shapiro, 2005).

The shipper has a stronger voice, illustrated by the unidirectional contract communication and provision of the overall structure for what to communicate (mode and content). The voice of the $3 \mathrm{PL}$ is sometimes disregarded by the shipper such as when they do not adapt contract requirements to the transport context or they continually monitor instead of engaging in dialogue. This indicates information asymmetries between the shipper and the 3PL, both through information overload (context non-specific requirements) and a lack of information, affecting the actors' ability to understand one another's requirements and capabilities, which is in line with the findings of Cambra-Fierro and Polo-Redondo (2008) and Prahinski and Benton (2004). Explanations for the information asymmetry could be cultural or rather industrial distance, between product and transport supply chains (Sauer and Seuring, 2018; Tachizawa and Wong, 2014). The information asymmetries may cause agency problems, preventing the $3 \mathrm{PL}$ from working with the shipper's best interests in mind. To some extent, the shipper does allow the 3PL's voice to be heard and acknowledges its legitimacy, by not micro-managing them in relation to developing their own work routines for meeting certain requirements. The outcome-oriented contract requirements for environmental sustainability clarify the goals of the shipper yet allows the 3PL to develop the work routines and solutions to meet them. Thus, the contract supports the agent and enables working in the best interest of the principal. When outcome measurability is low and is difficult to observe and assess (Selviaridis and Norrman, 2014) such as with social sustainability, a more behavior-oriented and process-focused contract is preferred.

No genuine partnership can be discerned. The communication perspective reveals that the shipper-controlled, autonomous communication is not fully aligned with the described relational structure. The $3 \mathrm{PL}$ is dependent on the powerful shipper and is exchangeable at every contract renewal. The relationship is not clearly based on trust, which is a central aspect of a relational structure (Aßländer et al., 2016; Varoutsa and Scapens, 2015; Mohr and Nevin, 1990). The lack of shipper trust is seen in the 3PL needing to accept various forms of formal, unidirectional monitoring.
The ethics that dominate this dyad are those of the shipper. The 3PL is expected to acknowledge the shipper's ethics, which are presented in the contract (following Ciliberti et al., 2011). The reliance on the ethics of a single actor opens the door to goal conflicts in the relationship, as the other actor is expected to follow but not be involved in setting performance goals (in line with Norrman and Näslund, 2019). In terms of social sustainability, the contract appendix lacks clear guidance, indicating information asymmetry with regard to what the principal wants to accomplish. This accords with the findings of, among others, Piecyk and Björklund (2015), who noted the lack of consensus on how to measure social sustainability in logistics services. The vague contract, in terms of performance goals, promotes increased legitimacy of the agents, as they are involved in defining the processes to ensure social sustainability in the TSC.

\subsubsection{Managerial challenges}

One concrete and urgent challenge concern the development of communication between the 3PL and the shipper: developing sustainability requirements that are context-relevant and able to be monitored or measured, which makes them possible to include in the contract (challenge 1). The contract requirements that are not relevant to the Swedish TSC context and that the shipper is unwilling to adapt represent a managerial challenge for the $3 \mathrm{PL}$ in extending sustainability across the TSC. Merely passing those requirements on unedited also passes on the identified information overload, which can spawn confusion or frustration (Mohr and Sohi, 1995). The empirical findings of Piecyk and Björklund (2015) exemplify sustainability measurements that are already applied in the transport industry and could be one point of departure for formulating requirements and measurements. To increase the context relevance and avoid agency problems, the ambitions of both the shipper and the 3PL must be considered, which calls for a more collaboration-oriented sustainability approach. The development of measurements could result in relevant and applicable monitoring, which could be used to track the performance of other LSPs as well. Instead of monitoring being seen only as an enabler of collaboration (in line with, e.g. Krause et al., 2000), collaboration could pave the way for better monitoring. The synergies found in applying both approaches are acknowledged (Aßländer et al., 2016; Tachizawa et al., 2015; Gimenez and Sierra, 2013). This would also address the need to develop relevant, operationalized measures of social sustainability (Nakamba et al., 2017) and to bridge information asymmetries (Foerstl et al., 2010). As the contract is forwarded along with the TSC, this challenge and its solutions, extend across the supply chain.

A predicted managerial challenge for the shipper is taking on a mediating role between consumers and the transport industry (challenge 2). As sustainable transports do not meet consumers the way sustainable products do (as suggested by Schmidt et al., 2017), the shipper may choose to give product suppliers priority (Kudla and Klaas-Wissing, 2012). Historically, the consumers' voice has not been a motive for sustainability in transport and very little transport-related communication has occurred between shippers and consumers. Some indications show that, due to increased e-commerce, this is about to change (Sallnäs and Björklund, 2020). When consumers start 
requiring more sustainable transports, socially responsible supply chains could be the result (Hoejmose et al., 2013; Cox, 2001). This development favors the more sustainable actors in the transport industry and it alters the power dynamic in their favor and that of the consumer. This development can also be understood to alter the roles of principals and agents. If their voice is strong enough, consumers can become the principals of the TSC in relation to transport sustainability and the shipper will be required to take on the mediating role of the secondary principal. In this specific case, such a development would fulfill the 3PL's wish to be more collaborative and to be proactive in relation to sustainability, as is expected in high-pollution industries (Tachizawa and Wong, 2014). This can support the 3PL in creating a more collaborative SCR-oriented sustainability approach in the TSC. If the shipper manages to take on this challenge, positive consequences can potentially be seen across the supply chain.

\subsection{The third-party logistics firms-hauler dyad}

In the 3PL-hauler dyad, both formal and informal modes of communication are used, containing content with both direct and indirect requests for hauler actions. The relationship is described as profound, long-term, interdependent and partnership-like, with a trust-based supportive climate and a high level of power symmetry (see Table 1 for traceability).

\subsubsection{Sustainability approach}

This dyad is represented by features that predominantly indicate an SCR approach. The sustainability approach between the 3PL and the hauler is characterized by a dyad-wide commitment to achieving sustainability that is underlined by an absence of mentioned goal conflicts (indicated by the wish to keep the shipper's contract), along with similar views on the importance of sustainable transports. The shipper's contract is passed on from the 3PL to the hauler and the shipper's monitoring of the 3PL gives rise to the monitoring of the hauler, as expected for the 3PL's double agency role (Meqdadi et al., 2020; Vlachos and Dyra, 2020; Wilhelm et al., 2016). The 3PL interprets the content of the contract and discusses and agrees with the hauler (farther down in the TSC) on what actions to take to address the stated contractual requirements. As in the shipper-3PL dyad, a potential goal conflict on the operational level can anyway be discerned: the hauler does not fully accept the social sustainability requirements posed by the shipper and they question the shipper's use of non-compliance clauses for delivery precision, as none are used for sustainability. This leads the hauler to disregard sustainability when the two goals are in conflict. The lack of non-compliance clauses related to environmental sustainability has been acknowledged by Björklund and Forslund (2013). The hauler perceives it to be the role of the $3 \mathrm{PL}$, as the holder of the contract, to actively seek to alter those requirements higher up in the TSC when they are understood as not being practically achievable. This is another illustration of the dual role of the 3PL as the secondary principal, confirming the "brokerage" role of LSPs in bridging the information asymmetries mentioned by Vlachos and Dyra (2020). This role may be specifically elaborate in the TSC context, as the 3PL acts on the primary principal's behalf and on the behalf of the hauler, as one of the owners (principals) of the 3PL.
The voices of both actors are identified as legitimate, revealed by their high-frequency and bidirectional collaborative communication (Mohr and Nevin, 1990), which is necessary for both buyers and suppliers to understand each other (Kembro et al., 2017; Cambra-Fierro and Polo-Redondo, 2008). To acknowledge all actors' views on relationships and their voices, an expansion of the terminology of "primary principal" and "secondary principal" (Cheng and Kam, 2008) is suggested: secondary agent (here, the hauler). In its role as the secondary principal, the 3PL mediates the communication between the shipper (i.e. the primary principal) and the hauler (i.e. the secondary agent). They mediate downward in various ways such as by orally clarifying interpretations of the requirements, jointly working to operationalize certain requirements and suggesting follow-up actions to the haulerthereby ensuring that information symmetry characterizes the 3PL-hauler dyad. The information symmetry facilitates a better understanding of the sustainability requirements (CambraFierro and Polo-Redondo, 2008). Additionally, the 3PL mediates upward by collecting, aggregating and extending certain measurement data from this hauler (and others) and they also prevent the hauler from providing additional measurement data directly to the shipper. In this way, they silence the voice of the hauler and fulfill the shippers' wishes to not receive information. The $3 \mathrm{PL}$ also monitors the secondary agent - which concurs with Meqdadi et al. (2020), who suggested that monitoring often cascades through the supply chain. However, the collaborative aspects are contrary to the findings of Villena and Gioia (2018), who instead primarily identified monitoring between first- and second-tier suppliers.

The 3PL-hauler dyad displays many aspects of a genuine partnership (Varoutsa and Scapens, 2015), as shown by their profound and interdependent relational structure, their trustbased supportive climate and their relatively symmetrical power. From an agency theory perspective, the 3PL is the principal in relation to the hauler or the secondary agent (Wilhelm et al., 2016; Ketchen and Hult, 2007); however, based on the cooperative ownership structure, the hauler is also, on an overall level, one of many principals of the 3PL, in whose interest the $3 \mathrm{PL}$ is expected to act. This is perceived as an explanation of the collaborative and interdependent relationship. However, the relationship is also complex, as the hauler, in its role as the principal of the 3PL, expects the 3PL to act with more power toward the shipper in setting attainable social sustainability requirements. In this regard, an agency problem can be identified as the agent (the 3PL) does not manage to act in the best interest of the principal (the hauler) and instead acts opportunistically (Shapiro, 2005).

The actors share the same ethics, stressing the importance of sustainability, both as an overall objective and as a factor affecting their competitive edge. However, the governing ethics that both the hauler and the 3PL are expected to acknowledge and follow are the ethics of the shipper, as displayed in their contract. According to Spence and Bourlakis (2009), not acknowledging all actors' ethics is consistent with a CSW approach.

\subsubsection{Managerial challenges}

Few significant managerial challenges to extending sustainability are identified in this dyad. However, the 
cooperative (hauler) ownership structure of the 3PL (challenge 3), common in Sweden, can to some extent explain the hauler's experience of the 3PL as ineffectual, due to the 3PL's inability to secure attainable social sustainability requirements. According to agency theory, the 3PL, in its role as secondary principal, has many secondary agents that operate within the same shipper contract; all those secondary agents need to be on board and adaptation to one single hauler is not possible. The hauler, as a secondary agent, is expected to adapt despite difficulties on an operational level. This example shows the dynamics of a situation wherein the hauler, as an owner, is also a principal in relation to the 3PL. This challenge may not affect other actors in this TSC, but it does affect the actors in the 3PL's network of haulers that are used to fulfill the contract.

\subsection{The shipper-hauler dyad}

Communication between the shipper and the hauler is largely transmitted through the $3 \mathrm{PL}$ and auditors. The communication frequency is low, the direction is unidirectional and the mode and content are formal and direct; the primary source of communication is the contract. Relations are described as long-term by the hauler and the shipper retains an arm's-length structure. The climate can be described as unsupportive and lacking in displays of trust, where power asymmetry prevails (Table 1 ).

\subsubsection{Sustainability approach}

This dyad is represented by features primarily indicating a CSW approach. A dyad-wide commitment to sustainability can be discerned in this indirect dyad, as both actors claim to prioritize sustainability; this indicates no goal conflict on an overall level. Despite being a lower-tier supplier that is not in direct contact with the consumer, the secondary agent displays no less sustainability ambition than does the shipper, which differs from the findings of Schmidt et al. (2017). The relatively high sustainability ambition of the second agent is supported by the findings of Tachizawa and Wong (2014), as firms in highpollution industries tend to be more proactive in their sustainability approach. Information asymmetries are identified in both actors' views. On an overall level, the primary principle has a better understanding of and information on what they want to accomplish in terms of sustainability, seen in Pratt and Zeckhauser (1985). However, in the view of the agent, this understanding is not fully applicable to the transport context; therefore, the secondary agent is understood to have better sustainability knowledge and more operational information. The hauler also tries to use this information to develop attainable sustainability requirements. This differs from the findings of Villena and Gioia (2018), Multaharju et al. (2017) and Faisal (2010), who showed that lower-tier suppliers and smaller companies in the supply chains of larger companies lack the resources, sustainability knowledge and interest to engage in efforts to achieve sustainability.

The voice of the second agent is silenced, as the principal prohibits communication of the sustainability status and disregard the hauler's suggestions for providing their own measurement reports directly to the principal. Again, the hauler's attempts diverge from what Fayezi et al. (2012) and Shapiro (2005) described when agents keep valuable information to themselves so as to better pursue their own interests. All information has to go through the 3PL (secondary principal); the information that does filter through has direct content (the contract) and is largely unidirectional from the shipper - i.e. autonomous communication. No feedback related to the operationalization of social sustainability requirements is received, which indicates unidirectional information sharing rather than bidirectional communication. Jonsson and Myrelid (2016) showed the potential of positive relational development and willingness to communicate; when lower-tier suppliers are allowed to communicate in a bidirectional way, their voice is supported. As such, in this case, the principal can be understood as reinforcing the identified information asymmetries. The power asymmetry allows the shipper to dictate how communication should occur, in line with the findings of, among others, Prahinski and Benton (2004). The shipper's actions are understood as a way of avoiding the complexities of long TSCs

This finding also indicates that no genuine partnership exists between the shipper and hauler. The shipper uses its asymmetrical power, based on the number of suppliers available (Pazirandeh and Norrman, 2014; Cox, 2001), to dictate the rules of the interaction and communication (also seen in the studies by Aßländer et al., 2016 and Biggemann, 2012). The shipper keeps the hauler at arm's length, shown by the use of third-party auditors, which is suggested by Tachizawa and Wong (2014) as a valid approach for handling lower-tier suppliers. In terms of how communication is handled, a goal conflict can be discerned. The primary ethics that are acknowledged are those of the shipper. The shipper's code of conduct, present in the contract, is the "measuring rod" of sustainability in the dyad.

\subsubsection{Managerial challenges}

The present sustainability approach in this indirect dyad reveals several challenges. One challenge is the lack of shipper understanding of the transport industry logic and structure (challenge 4), in line with the literature's acknowledgment of different distances in multi-tier supply chains (Sauer and Seuring, 2018). The shipper does not acknowledge that the TSC is long and consists of many small haulers, which is common in the fragmented transport industry (Evangelista, 2014). Contrary to the recommendations of Lo and Shiah (2016), the shipper does not put effort into their interactions with TSCs or listen to their voice so as to further their understanding of the transport industry. Instead, the shipper's operational understanding of the context is based on product supply chains, where the shipper has strong buyer competency and is accustomed to other ways of setting requirements and allocating responsibilities that involve fewer actors. Instead of communicating with multiple haulers, the shipper wants to have its single contract fulfilled, with no need to get involved in multiple transport-specific practices. This challenge becomes visible in other parts of the TSC as well such as in the noncontext- relevant requirements placed on the 3PL (see the first challenge in 4.1.2).

The challenge of silencing the hauler's voice (challenge 5) is related to the preceding managerial challenge. The distance between the actors increases the risk for information asymmetries and goal conflicts. This has previously been identified by Sauer and Seuring (2018), among others. 
According to agency theory, the agent is expected to create or sustain information asymmetries by withholding information to advance their position or to disguise their lack of effort (Sarkis et al., 2011). This expectation has not been confirmed by this study; instead, the hauler's actions are similar to the results of Aßländer et al. (2016), indicating that suppliers may be willing to act sustainably in a self-motivated way and to those of Meqdadi et al. (2020), who pointed at supplier willingness for compliance. Interestingly, the hauler is the actor who seeks to bridge information asymmetries by communicating and sharing more information, thereby indicating a principal problem instead of an agency problem. The shipper's reluctance to communicate collaboratively with the hauler might be explained by a perception of a low-risk setting, in which monitoring is recommended (Hajmohammad and Vachon, 2016). This challenge potentially undermines the development of sustainability in the TSC, as the competence of the hauler is not taken into account.

In relation to the contract, another managerial challenge is identified as the contract disincentivizes sustainability compliance (challenge 6). When delivery requirements conflict with the social sustainability requirements, delivery requirements are prioritized, as they come with non-compliance clauses. Jensen and Meckling (1976) advised principals to offer incentives to agents to better align their interests, particularly in outcomeoriented contracts, which require well-defined, measurable aspects of performance (Selviaridis and Norrman, 2014). Sustainability requirements do not always lend themselves to this description and, as delivery requirements do, a goal conflict emerges - not between actors, but between requirements. This challenge is related to the silencing of the hauler's voice and if this voice is not heard, the conflict will remain unattended.

A final managerial challenge is the shifting dynamics among LSPs (challenge 7). LSPs can act as 4PLs, 3PLs or haulers. In the frequent contract renewals, where the competitive environment of the industry becomes clear, former competitors can quickly turn into buyers and sub-contractors and hence enter into new constellations of principals and agents in relation to one another. The roles and, the associated power can change with the next contract renewal. Vlachos and Dyra (2020) recognized such situations as ones where certain actors have the power to configure new relations between principals and agents. In this sense, the challenge has the potential to affect the entire TSC and it affects the possibility of using different means to extend sustainability. The shifting dynamic and the resulting short-term relations, in a sense, prevent the use of more collaborative approaches to sustainability.

\section{Conclusions, contributions and further research}

To achieve the purpose "to explore sustainability approaches and managerial challenges in extending sustainability across a transport supply chain," sustainability approaches were studied in one multi-tier supply chain in a transport context, providing contributions to fill identified knowledge gaps (Ülgen et al., 2019; Sauer and Seuring, 2018; Evangelista et al., 2017). Sustainability approaches in the literature often simplify the fact that supply chains span several dyadic relations that can differ in character. This study found that features of the CSW approach are present in all the dyads studied, while a more
SCR-oriented approach can be discerned in the 3PL-hauler dyad, confirming the presence of mixed approaches.

The study contributes to the literature. LSPs, though present in almost every interface in supply chains, are seldom addressed in supply chain sustainability research. Seven managerial challenges in extending sustainability across the TSC were identified that are connected to the intersection of the shipper's product-related sustainability approach and the specific circumstances within the transport context. The lack of shipper understanding of the transport industry's logic and structure is central. Shippers may put less priority on their relations with LSPs compared to their relations with a product supplier. The fact that the study does not examine a product supply chain, a core of the retailer's operations, may explain the CSW approach. These findings expand the challenge related to different types of distances in supply chains (Sauer and Seuring, 2018) to include the distance between industries. Furthermore, the challenge of changing dynamics and the challenge of a cooperative ownership structure are common within the transport context. The impact of the applied contract is also fundamental. Given that social sustainability is difficult to measure and even to monitor on a continual basis, neither outcome-oriented nor behavior-oriented contracts are fully equipped to represent it. This is an important challenge to address to improve social sustainability in TSCs. The challenge is also seen in the complexity of conflicting contract requirements, leading to the non-intended disincentivization of sustainability. The managerial challenges related to the contract shed light on the challenge of differing priorities in supply chains, which is in line with findings of Kudla and Klaas-Wissing (2012) and they expand the findings of Björklund and Forslund (2013) to identify an absence of noncompliance clauses related to social sustainability.

Addressing the research gap of multi-tier supply chains led to the identification of multiple challenges in the indirect dyad. The shipper's lack of understanding of the transport context and the silencing of the hauler's voice hinder dialogue and feedback and suppress ideas for improvement; these are further examples of the identified managerial challenges in extending sustainability across the TSC. They indicate the opposite of a previously-known challenge of agents keeping valuable information to themselves (Sarkis et al., 2011). Just as for the expected challenge, when consumers increasingly require sustainable transports, the mediating role of TSC actors is crucial. The study further showed that the challenges are related to each other such as when a lack of context understanding (challenge 4) leads to the contract including sustainability requirements that are not adapted to the context (challenge 1), creating an information overload in the TSC. These challenges are also related to the silencing of the hauler's voice (challenge 5) and conflicting contract requirements, which are seen as disincentivizing sustainability (challenge 6). Several managerial challenges were associated with the sustainability approach feature of "each actor's voice," which, in turn, is associated with the communication. This strengthens the relevance of including communication as a literature perspective in studies of sustainability approaches.

The application of agency theory resulted in a deeper understanding of sustainability approaches beyond dyads, as called for by Aßländer et al. (2016) and Kudla and Klaas- 
Wissing (2012). It revealed interesting principal problems (as opposed to the expected agency problems) and questioned the basic premise of the agent's self-interest. Understanding the TSC-specific situation - in which actors frequently move from being a competitor to being a sub-contractor or are a subcontractor in one relationship and a buyer in another (i.e. entering the roles of principal and agent) - could be the first step in a relevant contribution to agency theory. The cooperative ownership between the 3PL and the hauler also involves shifting principal-agent roles, where the hauler is both principal and agent to the 3PL. The competitive situation, where LSPs are exchangeable at every contract renewal, decreases the likelihood that the sustainability approach can go beyond monitoring and confirms the challenge of the fragmented transport industry (Evangelista, 2014). Based on this study, consumers and drivers were identified as potential actors involved in sustainability approaches across the TSC; to address these actors, labels such as "tertiary principals" and "tertiary agents" are suggested. This expands the terminology of Cheng and Kam (2008) and can enable the further application of agency theory in multi-tier supply chains. Additional actors such as auditors and spot-checking companies can also be identified as external or indirect actors (e.g. indirect principals or agents) who are outside the main multi-tier supply chain yet play an important part in extending sustainability throughout the chain.

Managerial contributions can be found in the understanding and awareness of various challenges, enabling managers to mitigate or avoid them in TSC operational contexts. By handling these challenges, managers could further develop their sustainability approach across the TSC, with higher sustainability performance as an expected result. Another managerial contribution consists of the insights from and acknowledgment of different actors' views. The case study method provides new insights into collaboratively improving sustainability in supply chains, adding implications for environmental and social sustainability.

This study and its results are likely to have external validity. The theoretical model based on complementary literature perspectives could also be applied to other areas - such as risk, resilience or innovation - that need to be extended across a supply chain. The literature and methodology applied are not only transport-specific, and thus could likewise be applied to studying sustainability approaches in product supply chains. This study provides insights into the importance of not only analyzing chains but finding details in the dyads.

The study had some limitations that could be addressed by further research. The access to this unique shipper led to the study of just one TSC. This TSC, operating in Sweden, consisted of certain actors and company sizes and used road transport mode and dedicated truckloads. Further research can test the external validity of these findings. As the Swedish context is understood to be highly developed in terms of sustainability, research in another geographic context could very well generate different results. A study of a small shipper and a powerful global 3PL could also expand the current findings.

Although several actors in the TSC were studied, examining other actors - such as drivers, consumers, auditors and spotchecking companies - could broaden the view on sustainability approaches and managerial challenges. One way to include other actors is to venture beyond one-to-one relations, investigating the same phenomena in one-to-many networks. Exploring how different haulers handle relations and communication in line with the principal's ambitions or how they manage the differing ambitions of multiple principals, could hold similarities with supplier development, where the supplier is developed by many buyers simultaneously (as addressed by Ülgen, 2020). This could also lead to the study of less-than-truckload TSCs, which is a large share of transported goods. The current study revealed more complex TSCs that should be the subject of further research such as a 3PL acting as a 4PL between a shipper and other 3PLs or the same hauler driving for both 3PLs and 4PLs. In other situations, haulers can have not only employed drivers but also small, self-employed drivers (i.e. one individual/one vehicle), which could add actors and make the relations across TSCs even more complex. Actors' changing roles in the TSC and an agent becoming a principal, would be highly relevant for further study, potentially with longitudinal, interactive research methodologies.

A final suggestion concerns developing sound contracts in a TSC. Outcome-oriented contracts are found to work well for environmental sustainability requirements, while for the difficult-to-measure social sustainability requirements, agency theory leaves us with behavior-oriented contracts. This would require monitoring of the LSPs' behaviors and processes something that would come at a high agency cost. Given the situation found in the TSC, with little interest from the shipper's side, this seems an unlikely situation. Thus, the third orientation of contracts seems to be needed. Potentially, a collaborative SCR approach wherein the actors trust and acknowledge each other can pave the way to such a contract orientation or even replace it. This suggestion would also require more research.

\section{Note}

1 The 3PL has been ISO 14001-certified since 2001. It began to conduct sustainability reporting in 2008 (sustainability reporting has been a mandatory legal requirement in Sweden since 2016). It has also had a pioneering role in developing an infrastructure for alternate fuels such as HVO100 (the 3PL's webpages).

\section{References}

Ashby, A., Leat, M. and Hudson-Smith, M. (2012), "Making connections: a review of supply chain management and sustainability literature", Supply Chain Management: An International fournal, Vol. 17 No. 5, pp. 497-516.

Aßländer, M.S., Roloff, J. and Nayir, D.Z. (2016), "Supplier as stewards? Managing social standards in first-and second tier suppliers", Fournal of Business Ethics, Vol. 139 No. 4, pp. 661-683.

Awan, U. (2019), "Impact of social supply chain practices on social sustainability performance in manufacturing firms", International fournal of Innovation and Sustainable Development, Vol. 13 No. 2, pp. 198-219. 
Biggemann, S. (2012), "The essential role of information sharing in relationship development", Fournal of Business $\mathcal{E}$ Industrial Marketing, Vol. 27 No. 7, pp. 521-526.

Björklund, M. and Forslund, H. (2013), "The inclusion of environmental performance in transport contracts", Management of Environmental Quality: An International Fournal, Vol. 24 No. 2, pp. 214-227.

Bryman, A. and Bell, E. (2011), Business Research Methods, Oxford University Press, New York, NY.

Cambra-Fierro, J. and Polo-Redondo, Y. (2008), "Creating satisfaction in the demand-supply chain: the buyer's perspective", Supply Chain Management: An International fournal, Vol. 13 No. 3, pp. 211-224.

Cao, M., Vonderembse, M.A., Zhang, Q. and Ragu-Nathan, T.S. (2010), "Supply chain collaboration: conceptualization and instrument development", International fournal of Production Research, Vol. 48 No. 22, pp. 6613-6635.

Centobelli, P., Cerchione, R. and Esposito, E. (2017), "Environmental sustainability in the service industry of transportation and logistics service providers: systematic literature review and research directions", Transportation Research Part D: Transport and Environment, Vol. 53, pp. 454-470.

Centobelli, P., Cerchione, R. and Esposito, E. (2020), "Pursuing supply chain sustainable development goals through the adoption of green practices and enabling technologies: a cross-country analysis of LSPs", Technological Forecasting E Social Change, Vol. 153.

Cheng, S.K. and Kam, B.H. (2008), "A conceptual framework for analysing risk in supply networks", Fournal of Enterprise Information Management, Vol. 21 No. 4, pp. 345-360.

Ciliberti, F., de Haan, J., de Groot, G. and Pontrandolfo, P. (2011), "CSR codes and the principal-agent problem in supply chains: four case studies", Fournal of Cleaner Production, Vol. 19 No. 8, pp. 885-894.

Cloutier, C., Oktaei, P. and Lehoux, N. (2020), “Collaborative mechanisms for sustainability-oriented supply chain initiatives: state of the art, role assessment and research opportunities", International fournal of Production Research, Vol. 58 No. 19, pp. 5836-5850.

Cox, A. (2001), "Understanding buyer and supplier power: a framework for procurement and supply competence", Fournal of Supply Chain Management, Vol. 37 No. 1, pp. 8-15.

Eisenhardt, K.M. (1989), "Agency theory: an assessment and review", Academy of Management Review, Vol. 14 No. 1, pp. 57-74.

Eriksson, D. and Svensson, G. (2015), "Elements affecting social responsibility in supply chains", Supply Chain Management: An International fournal, Vol. 20 No. 5, pp. 561-566.

Evangelista, P. (2014), "Environmental sustainability practices in the transport and logistics service industry: an exploratory case study investigation", Research in Transportation Business E Management, Vol. 12, pp. 63-72.

Evangelista, P., Colicchia, C. And Creazza, A. (2017), "Is environmental sustainability a strategic priority for logistics service providers?", Fournal of Environmental Management, Vol. 198, pp. 353-362.

Faisal, M.N. (2010), "Analyzing the barriers to corporate social responsibility in supply chains: an interpretive structural modelling approach", International fournal of Logistics Research and Applications, Vol. 13 No. 3, pp. 179-195.
Fayezi, S., O'Loughlin, O. and Zutshi, A. (2012), “Agency theory and supply chain management: a structured literature review", Supply Chain Management: An International fournal, Vol. 17 No. 5, pp. 556-570.

Foerstl, K., Reuter, C., Hartmann, E. And Blome, C. (2010), "Managing supplier sustainability risks in a dynamically changing environment - sustainable supplier management in the chemical industry", Fournal of Purchasing and Supply Management, Vol. 16 No. 2, pp. 118-130.

Ghijsen, P.W.T., Semeijn, J. and Ernstson, S. (2010), "Supplier satisfaction and commitment: the role of influencing strategies and supplier development", fournal of Purchasing and Supply Management, Vol. 16 No. 1, pp. 17-26.

Gimenez, C. and Sierra, V. (2013), "Sustainable supply chains: governance mechanisms to greening suppliers", fournal of Business Ethics, Vol. 116 No. 1, pp. 189-203.

Gong, Y., Jia, F., Brown, S. and Koh, L. (2018), "Supply chain learning of sustainability in multi-tier supply chains", International fournal of Operations E Production Management, Vol. 38 No. 4, pp. 1061-1090.

Hajmohammad, S. and Vachon, S. (2016), "Mitigation, avoidance, or acceptance? Managing supplier sustainability risk", fournal of Supply Chain Management, Vol. 52 No. 2, pp. 48-65.

Hoejmose, S.U., Grosvold, J. and Millington, A. (2013), "Socially responsible supply chains: power asymmetries and joint dependence", Supply Chain Management: An International fournal, Vol. 18 No. 3, pp. 277-291.

Jadhav, A., Orr, S. and Malik, M. (2019), "The role of supply chain orientation in achieving supply chain sustainability", International fournal of Production Economics, Vol. 217 No. November, pp. 112-125.

Jensen, M.C. and Meckling, W.H. (1976), "Theory of the firm: managerial behavior, agency costs and ownership structure", Fournal of Financial Economics, Vol. 3 No. 4, pp. 305-360.

Jiang, B. (2009), "The effects of interorganizational governance on supplier's compliance with SCC: an empirical examination of compliant and non-compliant suppliers", Foumal of Operations Management, Vol. 27 No. 4, pp. 267-280.

Jonsson, P. and Myrelid, (2016), " "Supply chain information utilisation: conceptualization and antecedents", International Fournal of Operations \& Production Management, Vol. 36 No. 12, pp. 1969-1779.

Kembro, J., Näslund, D. and Olhager, J. (2017), “Information sharing across multiple supply chain tiers: a Delphi study on antecedents", International fournal of Production Economics, Vol. 193, pp. 77-86.

Kent, J. and Mentzer, J.T. (2003), "The effect of investment in interorganizational information technologies in a retail supply chain”, fournal of Business Logistics, Vol. 24 No. 2, pp. 155-175.

Ketchen, J.D.J. and Hult, G.T.M. (2007), "Bridging organization theory and supply chain management: the case of best value supply chains", fournal of Operations Management, Vol. 25 No. 2, pp. 573-580.

Krause, D., Scannell, T. and Calantone, R. (2000), "A structural analysis of the effectiveness of buying firms' strategies to improve supplier performance", Decision Sciences, Vol. 31 No. 1, pp. 33-55.

Kudla, N.L. and Klaas-Wissing, T. (2012), "Sustainability in shipper-logistics service provider relationships: a tentative taxonomy based on agency theory and stimulus-response 
analysis", Fournal of Purchasing and Supply Management, Vol. 18 No. 4, pp. 218-231.

Lee, S. and Klassen, R.D. (2008), "Drivers and enablers that foster environmental management capabilities in small- and medium sized suppliers in supply chains", Production and Operations Management, Vol. 17 No. 6, pp. 573-586.

Li, L., Wang, Y. and Dai, W. (2013), “Coordinating a supply chain with transport service providers", fournal of Industrial and Production Engineering, Vol. 30 No. 2, pp. 105-116.

Lo, S.L. and Shiah, Y.A. (2016), "Associating the motivation with the practices of firms going green: the moderator role of environmental uncertainty", Supply Chain Management: An International fournal, Vol. 21 No. 4, pp. 485-498.

Meqdadi, O., Johnsen, T.E., Johnsen, R.E. and Salmi, A. (2020), "Monitoring and mentoring strategies for diffusing sustainability in supply networks", Supply Chain Management: An International fournal, Vol. 25 No. 6, pp. 729-746.

Mohr, J. and Nevin, J.R. (1990), "Communication strategies in marketing channels: a theoretical perspective", fournal of Marketing, Vol. 54 No. 4, pp. 36-51.

Mohr, J. and Sohi, R.S. (1995), "Communication flows in distribution channels: impact on assessments of communication quality and satisfaction", Fournal of Retailing, Vol. 71 No. 4, pp. 393-416.

Mohr, J., Fisher, R.J. and Nevin, J.R. (1996), "Collaborative communication in interfirm relationships: moderating effects of integration and control", fournal of Marketing, Vol. 60 No. 3, pp. 103-115.

Multaharju, S., Lintukangas, K., Hallikas, J. And Kähkönen, A. (2017), "Sustainability-related risk management in buying logistics services: an exploratory cross-case analysis", International Fournal of Logistics Management, Vol. 28 No. 4, pp. 1361-1367.

Nakamba, C.C., Chan, P.W. and Sharmina, M. (2017), "How does social sustainability feature in studies of supply chain management? A review and research agenda", Supply Chain Management: An International foumal, Vol. 22 No. 6, pp. 522-541.

Norrman, A. and Näslund, D. (2019), "Supply chain incentive alignment: the gap between perceived importance and actual practice", Operations and Supply Chain Management, Vol. 12 No. 3, pp. 129-142.

Paulraj, A., Lado, A. And Chen, I. (2008), "Interorganizational communication as a relational competency: antecedents and performance outcomes in collaborative buyer-supplier relationships", fournal of Operations Management, Vol. 26 No. 1, pp. 45-64.

Pazirandeh, A. and Norrman, A. (2014), "An interrelation model of power and purchasing strategies: a study of vaccine purchase for developing countries", fournal of Purchasing and Supply Management, Vol. 20 No. 1, pp. 41-53.

Piecyk, M.I. and Björklund, M. (2015), "Logistics service providers and corporate social responsibility: sustainability reporting in the logistics industry", International fournal of Physical Distribution $\mathcal{E}$ Logistics Management, Vol. 45 No. 5, pp. 459-485.

Prahinski, C. and Benton, W.C. (2004), "Supplier evaluations: communication strategies to improve supplier performance", Fournal of Operations Management, Vol. 22 No. 1, pp. 39-62.

Pratt, J.W. and Zeckhauser, R.J. (1985), Principals and Agents: The Structure of Business, Harvard Business School Press, Boston, MA.
Sallnäs, U. and Björklund, M. (2020), “Consumers' influence on the greening of distribution - exploring the communication between logistics service providers, e-tailers and consumers", International fournal of Retail $\mathcal{E}$ Distribution Management, Vol. 48 No. 11, pp. 1177-1193.

Sancha, C., Gimenez, C. and Sierra, V. (2016), “Achieving a socially responsible supply chain through assessment and collaboration", Fournal of Cleaner Production, Vol. 112 No. Part 3, pp. 1934-1947.

Sarkis, J., Zhu, Q. and Lai, K. (2011), “An organizational theoretic review of green supply chain management literature", International fournal of Production Economics, Vol. 130 No. 1, pp. 1-15.

Sauer, P.C. and Seuring, S. (2018), "A three-dimensional framework for multi-tier sustainable supply chain management", Supply Chain Management: An International Fournal, Vol. 23 No. 6, pp. 560-572.

Schmidt, C.G., Foerstl, K. and Schaltenbrand, B. (2017), "The supply chain position paradox: green practice and firm performance", fournal of Supply Chain Management, Vol. 53 No. 1, pp. 3-25.

Selviaridis, K. and Norrman, A. (2014), "Performance-based contracting in service supply chains: a service provider risk perspective", Supply Chain Management: An International fournal, Vol. 19 No. 2, pp. 153-172.

Shapiro, S.P. (2005), "Agency theory", Annual Review of Sociology, Vol. 31 No. 1, pp. 263-284.

Soosay, C.A. and Hyland, P. (2015), "A decade of supply chain collaboration and directions for future research", Supply Chain Management: An International fournal, Vol. 20 No. 6, pp. 613-630.

Spence, L. and Bourlakis, M. (2009), "The evolution from corporate social responsibility to supply chain responsibility: the case of Waitrose", Supply Chain Management: An International fournal, Vol. 14 No. 4, pp. 291-302.

Tachizawa, E.M. and Wong, C.Y. (2014), "Towards a theory of multi-tier sustainable supply chains: a systematic literature review", Supply Chain Management: An International fournal, Vol. 19 Nos 5/6, pp. 643-663.

Tachizawa, E.M., Gimenez, C. and Sierra, V. (2015), “Green supply chain management approaches: drivers and performance implications", International fournal of Operations \& Production Management, Vol. 35 No. 11, pp. 1546-1566.

Ülgen, S.V. (2020), "Supplier development within and beyond the dyad - focusing on suppliers' experiences", Doctoral thesis, Linnaeus University Press, Växjö, Sweden.

Ülgen, S.V., Björklund, M., Simm, N. and Forslund, H. (2019), "Inter-organizational supply chain interaction for sustainability - a systematic literature review", Sustainability, Vol. 11 No. 19, p. 5488.

Varoutsa, E. and Scapens, R.W. (2015), "The governance of inter-organizational relationships during different supply chain maturity steps", Industrial Marketing Management, Vol. 46 No. 1, pp. 68-82.

Villena, V.H. and Gioia, D.A. (2018), "On the riskiness of lower-tier suppliers: managing sustainability in supply networks", fournal of Operations Management, Vol. 64 No. 1, pp. 65-87. 
Vlachos, I. and Dyra, S.C. (2020), “Theorizing coordination, collaboration and integration in multi-sourcing triads (B3B triads)", Supply Chain Management: An International fournal, Vol. 25 No. 3, pp. 285-300.

Wilhelm, M.M., Blome, C., Bhakoo, V. and Paulraj, A. (2016), "Sustainability in multi-tier supply chains: understanding the double agency role of the first-tier supplier", fournal of Operations Management, Vol. 41 No. 1, pp. 42-60.

Yin, R.K. (2014), Case Study Research: Design and Methods, (5th ed.), Sage, Thousand Oaks, CA.

\section{Appendix. Interview guide}

\section{General questions:}

Describe your current position, title and "history" (both within the company and in previous employments, if relevant)

Give an overview of this transport supply chain and its actors

\section{Questions on relations:}

For each of the supply chain actors: What is the nature of the relationship formed (regarding sustainability) with the other actors in the supply chain?

Probing areas, form questions to capture every concept:

- Description of the structure; (the inter-organizational interaction ranging from market to partnership, by describing the degree of joint planning, length of relation and interdependencies)

- Description of the climate (the feeling about the level of trust and supportiveness in the relation)
- Description of the power (the degree of symmetrical to asymmetrical power balance)

\section{Questions on communication:}

For each of the supply chain actors: What communication (on sustainability) takes place with the other actors in the chain?

Probing areas, form questions to capture every concept:

- Description of communication frequency (how often and how much (too little/too much) different types of information is communicated (contracts, measurement reports, etc.)

- Description of communication direction (from unidirectional to bidirectional/dialogue and feedback)

- Description of communication mode (from formal (planned, routinized and structured) to informal (personalized, irregular and spontaneous also outside formal lines of communication). What tools assist in doing this (software, apps, etc.)

- Description of communication content; from direct (seeks to change the communications partner's behavior by requesting the performance of specific actions) to indirect (seeks to align the attitudes of the communication partner with the desired behavior but without requesting actions)

\section{Corresponding author}

Helena Forslund can be contacted at: helena.forslund@lnu. se

For instructions on how to order reprints of this article, please visit our website:

www.emeraldgrouppublishing.com/licensing/reprints.htm

Or contact us for further details: permissions@emeraldinsight.com 